\title{
ATÉCNICA ESPORTIVA COMO CONSTRUÇÃO CULTURAL: IMPLICAÇÕES PARA A PEDAGOGIA DO ESPORTE
}

\author{
Jocimar Daolio \\ Professor livre-docente da Faculdade de Educação Física da Unicamp (SP) e coordenador do Grupo de Estudo e Cultura \\ Educação Física e Cultura.
}

\author{
Emerson Luís Velozo \\ Professor da Universidade Estadual do Centro-Oeste (PR) e doutorando da Faculdade de Educação Física da Unicamp.
}

\begin{abstract}
Resumo
O texto discute a técnica esportiva, com base em alguns referenciais das ciências sociais e humanas, e faz um contraponto ao conceito tradicional de técnica utilizado pela área de Educação Física e Esporte, cuja fundamentação teórica é composta primordialmente por contribuições das ciências da natureza. Considerando a técnica como o conjunto de modos de fazer e a tática como as razões do fazer, o texto trata das implicações para a pedagogia do esporte, propondo o ensino da cultura esportiva de forma mais democrática, singular e autoral, respeitando as especificidades culturais e as constantes ressignificações do esporte.

Palavras-chave: esporte - cultura esportiva - pedagogia do esporte - técnica esportiva.
\end{abstract}

$\mathrm{O}$ objetivo deste trabalho é discutir a técnica esportiva considerando os referenciais das ciências sociais e humanas, fazendo um contraponto ao conceito tradicional de técnica utilizado pela área de Educação Física e Esporte, cuja base teórica é composta primordialmente por contribuições das ciências da natureza. De fato, quando se discute o conceito de técnica utilizado pela área, não raro se lança mão de conhecimentos da biomecânica, da fisiologia do exercício, e até mesmo da física e da biologia, para justificar determinados procedimentos pedagógicos em busca do movimento técnico perfeito. Aliás, é curioso notar que a palavra "técnica" tradicionalmente é usada como sinônima de movimento correto, daí advindo expressões como "gesto não técnico" ou "movimento sem técnica". De substantivo feminino (a técnica como um processo ou um saber) a palavra passou a ser usada como adjetivo (forma técnica ou expressão técnica), chegando finalmente, com a adição do sufixo "mente", a um advérbio (tecnicamente, significando "maneira técnica").

É importante observar que, para Gilles-Gaston Granger (1994), a técnica é uma prática humana anterior à ciência, vinculada, na Antigüidade, à dimensão da arte, e o seu princípio estava no criador e não na criação. A técnica associada à arte se constituía como um modo de fazer que era tradicional, ou seja, seguia determinados costumes e rituais próprios de um grupo ou de uma região. No entanto, com o decorrer da história, a técnica foi penetrada pelo saber científico. Alguns exemplos como a manufatura de relógios, a da máquina a vapor e a da radioeletricidade demonstram a incorporação de conhecimentos científicos nas criações técnicas. Nestes três casos, a técnica, que até o século XVII era derivada da engenhosidade e da habilidade dos artesãos, passa a incorporar dados da ciência para sua realização (GRANGER, 1994). O autor distingue as técnicas empíricas das téc- 
nicas científicas, sendo as primeiras vinculadas às experiências práticas e ainda não penetradas pelo saber científico. Essas técnicas ou saberes, que compõem o chamado senso comum, são transmitidos essencialmente pela tradição oral e, ainda que possam estar associados às crenças supersticiosas, são igualmente eficazes. As segundas - as científicas - estão fundamentadas em explicações teóricas, ao caráter desinteressado e à capacidade de demonstração ou de explicação própria das ciências.

Tanto as técnicas empíricas quanto as científicas são saberes válidos. A questão central é que a técnica ainda não penetrada pela ciência, aquela que se associava à arte e à tradição, como o trabalho do artesão, possuía um maior grau de singularidade, exprimindo algo - uma intenção, uma criação, um estilo, uma idiossincrasia - do seu executante. A cientificização das técnicas acabou, justamente, por diminuir o grau de singularidade destas e, ao mesmo tempo, fez aumentar o grau de normalização. A partir do século XVIII, com a revolução industrial européia, a relação entre teoria científica e técnica, que antes era relativamente distante, se estreitou. A ciência penetrou a técnica e retirou desta a sua singularidade, o seu estilo, aquilo que a aproximava do mundo da arte. Uma conseqüência desse processo é a extrema racionalização, fragmentação e especialização das tarefas, como é o caso do taylorismo que, considerando a cronometragem rigorosa dos processos de produção e a extrema planificação das ações, objetivava elevar ao máximo o nível de rendimento (GRANGER, 1994). A transformação operada pela influência da ciência sobre a técnica tem como conseqüência a oposição entre a técnica vinculada à arte, na qual estava impressa a singularidade do criador, e a técnica extremamente normalizada, que serve à produção de massa. Essas mudanças, pelas quais a técnica tem passado, estão vinculadas às transformações das chamadas sociedades tradicionais para as sociedades modernas.
Ao contrário das chamadas sociedades tradicionais, a sociedade moderna é altamente fragmentada e especializada. Nas sociedades tradicionais, educação e instrução se confundem e não se separam no processo de uma educação total. Nelas não há grande especialização das tarefas como em nossa sociedade. Nesse sentido, a modernidade vem para superar a tradição e soterrar o seu modo de organização. No entanto, segundo Renato Ortiz (2007), tradição e modernidade não precisam ser pensadas como coisas opostas, o importante é qualificar o tipo de tradição a que nos referimos, como por exemplo, a tradição construída pela modernidade ou as diferentes tradições constituídas pelos diversos grupos indígenas. É preciso, observa Ortiz, analisar como estas diferentes tradições se articulam à modernidade-mundo.

O processo de transformação das tradições é radical no âmbito da modernidade. $\mathrm{Na}$ sociedade contemporânea, cuja cultura é mundializada (ORTIZ, 2007), certos elementos técnicos são retirados do seu lugar de origem e colocados num lugar de destaque, como referentes globalizados. Em relação às técnicas corporais, determinados gestos são colocados em movimento pela mundialização da cultura e a modernidade tende a universalizá-los. Contudo, não podemos esquecer que tais gestos técnicos são construções culturais que surgiram em contextos históricos e socialmente concretos, portanto, sua origem é local. Também não se pode perder de vista que a modernidade que se apresenta em nossa sociedade e sua pretensão de universalidade não ocorrem de forma justa e democrática em todos os contextos. Como conseqüência não são apenas as técnicas que se tornam universais, mas também as ideologias que surgem com elas. Isso explica porque determinados gestos técnicos tradicionais e eficazes no plano local são postos de lado em nome de certos "universais" na dinâmica da modernidade-mundo. Isso gera certas ideologias sobre as técnicas corporais 
que precisam ser rebatidas no plano simbólico.

O conceito de imitação prestigiosa, utilizado por Marcel Mauss (1974), segundo o qual os atos bem sucedidos de pessoas portadoras de "autoridade" tendem a ser imitados, pode ajudar a compreensão da dinâmica de mundialização de determinadas técnicas esportivas. Por exemplo, um gesto técnico como a conhecida "pedalada", divulgado pelo jogador de futebol Robinho (ex-jogador do Santos Futebol Clube e atuante no Real Madrid, da Espanha), é, certamente, dotado de eficácia simbólica para aqueles que prestigiam o jogador e é logo retirado do seu local de origem para ser transformado, geralmente pelos meios de comunicação, em um referente universal. Neste contexto, certas técnicas corporais tornam-se referentes que são postos na dinâmica mundial e tendem a ser universalizados.

Seguindo o que sugere Ortiz (2007) quando afirma que é preciso qualificar o tipo de tradição de que estamos falando e como ela se articula com a modernidade mundo, podemos inferir que a concepção de técnica que ainda inspira o ensino tradicional dos esportes está vinculada à tradição da modernidade. A super-especialização no ensino das técnicas esportivas está atrelada ao modelo de esporte de alto rendimento. Ela surge na dinâmica de profissionalização do esporte, sustentada pela exacerbação do uso de determinados tipos de técnica. A técnica referida é aquela nos moldes da ciência moderna, especificamente nos parâmetros de uma biodinâmica do movimento. A modernidade, ou melhor, a ciência moderna é a instituição que fundamenta o modelo de técnica tradicionalmente utilizado no ensino do esporte.

O nível de especialização do esporte moderno pode ser medido pelo aumento na profissionalização da intervenção pedagógica. O futebol, por exemplo, passa de uma modalidade esportiva organizada pelas próprias crianças, que se aprendia no campo de vár- zea, no quintal da casa, driblando os colegas, os buracos, os tocos, as pedras etc., para um nível de organização cada vez mais profissionalizado e especializado, contando com espaços mais "adequados", professores e materiais sofisticados. Estas são evidências do processo de modernização pelo qual também passam as modalidades esportivas. Em síntese, a dimensão que a técnica tem ocupado no ensino do esporte pode ser compreendida pela tríade "modernidade", "ciência moderna" e "esporte moderno".

O esporte moderno, segundo Valter Bracht (2005), surgiu no âmbito da cultura européia por volta do século XVIII, intensificando-se nos séculos XIX e XX num processo de rápida expansão aos demais países do mundo. Algumas expressões da cultura corporal de movimento, que se relacionavam tradicionalmente à comemoração de datas festivas, à colheita, aos rituais e outros, foram esportivizadas. $\mathrm{O}$ esporte na sua forma moderna foi uma modificação de expressões da cultura de movimento tradicional e, não por um mero acaso, cresceu e tornou-se hegemônico nos últimos séculos. É interessante observar que alguns princípios e valores que passaram a reger a nova sociedade capitalista industrial, estruturada a partir do século XIX, foram incorporados pelo esporte. Houve grande influência de um novo modo de vida - fruto da nova organização do trabalho nas fábricas e do conseqüente processo de urbanização - sobre os jogos e práticas tradicionais, esses sendo perpassados por características e elementos presentes nas novas formas de trabalho, como o rendimento, a fragmentação de conhecimentos e processos, a otimização do tempo, a produtividade, a economia de esforços entre outros. As novas práticas esportivas, que se estruturaram ao longo do século XIX, expressavam as mesmas características do trabalho nas fábricas, e esse fato permite compreender o estilo do esporte contemporâneo.

De acordo com Bracht (2005), o modelo de esporte predominante nos dias de hoje no 
Brasil é o de alto rendimento ou espetáculo, mesmo quando ele ocorre em instituições escolares ou no tempo/espaço destinado ao lazer. Esse modelo esportivo atual pressupõe a busca da perfeição técnica por parte de seus praticantes e sua prática rigidamente determinada pelas regras, técnicas e táticas de equipes competitivas. De fato, é possível presenciar atividades esportivas no tempo de lazer ou competições escolares praticadas com os códigos e valores do esporte de rendimento, como a busca feroz pelo primeiro lugar, a ansiedade pela vitória a qualquer preço, a rígida reprodução de regras e técnicas. Dessa forma, conforme Granger (1994), a técnica utilizada perde a autoria e a singularidade para ser, ao mesmo tempo, meio e fim da prática esportiva.

Este parece ser o sentido que a técnica adquiriu na área de Educação Física e Esporte, com implicações diretas para seu ensino: reduzido, fragmentado, mecanizado e racionalizado. A técnica tem sido vista tradicionalmente no ensino dos esportes por um viés estritamente mecanicista, no sentido de um meio que seja o mais eficiente para se realizar determinada ação. Por outro lado, ela também se torna fim, uma vez que a dimensão da estratégia de ação é supervalorizada. A dimensão da eficiência de execução da técnica é o centro da preocupação, por isso a característica tecnológica atribuída ao estudo das técnicas por certos estudiosos da Educação Física e Esporte.

$\mathrm{Na}$ Educação Física tradicional a técnica que não se assemelha com o gesto do atleta de alto nível, tido como referência, tende a ser vista como errônea ou de baixa qualidade, de modo que há a insistência em se dizer que o aluno não sabe praticar esporte se não realizar os movimentos de acordo com certas prescrições biomecânicas e fisiológicas. Assim, a técnica, na Educação Física, é penetrada pelas ciências naturais, primordialmente pela biomecânica e fisiologia do exercício, que dão suporte e ao mesmo tempo justificam um modelo de esporte de alto rendimento. Parafrase- ando Clifford Geertz (1989), a técnica esportiva tradicional seria vista pela área de Educação Física e Esporte numa perspectiva estratigráfica de natureza humana, a partir da qual o ser humano seria dividido em camadas, tendo o nível biológico como núcleo, superposto pelos estratos psicológico, social e cultural. Em outros termos, a dimensão cultural seria posterior e conseqüente ao componente biológico, este justificativo das causas do comportamento humano (GEERTZ, 1989).

Um exemplo é o livro de James G. Hay intitulado Biomecânica das técnicas desportivas, cuja intenção é fornecer um estudo científico sobre o movimento humano e sobre as técnicas esportivas e que teve no Brasil grande repercussão. Faz parte de uma coleção chamada "Biblioteca de Educação Física", composta por mais duas obras, Tratado de fisiologia do exercicio, de Per-Olof Astrand, e Medida e avaliação em Educação Física, de Donald K. Mathews. ${ }^{1}$ Este exemplo editorial ilustra o tipo de ciência que tradicionalmente penetrou o campo da Educação Física e que certamente contribuiu para a fundamentação da área com base no olhar das ciências da natureza.

Outros exemplos podem ser observados pela quantidade de livros e artigos da área de Educação Física e Esporte, principalmente aqueles destinados ao ensino das várias modalidades esportivas, que abordam a questão da técnica de forma instrumental. Uma determinada modalidade esportiva (o voleibol, por exemplo) é fragmentada a partir de suas técnicas (o toque, a manchete, a cortada, o saque, o bloqueio e assim por diante) e essas são divididas em estágios ou fases de uma seqüência pedagógica visando ao seu ensino. Assim, uma única maneira de executar um movimento esportivo torna-se o padrão de correção, e todas as outras formas são tidas como errôneas, incompletas ou varian-

\footnotetext{
1 Essas obras fazem parte da coleção Biblioteca de Educação Física, da Editora Interamericana, 2a edição, 1981.
} 
tes menos desejáveis da técnica considerada perfeita.

Em contraposição ao modelo de técnica oriundo das ciências da natureza, esboçaremos a noção de técnica corporal com base no olhar das ciências sociais e humanas, especificamente, do antropólogo francês Marcel Mauss (1872-1950). Segundo o autor, técnicas corporais são todas as formas de uso do corpo criadas pelos seres humanos em sociedade ao longo do tempo. Técnica, de acordo com Mauss, é um ato tradicional e eficaz. Para ele, não há técnica e nem transmissão se não houver tradição (MAUSS, 1974). As técnicas corporais "são os gestos simbólicos que são, ao mesmo tempo, gestos reais e fisicamente eficazes" (MAUSS, 2001, p. 115). Mauss equipara, dessa forma, as técnicas corporais às demais técnicas humanas, como as de cozimento de alimentos, as de plantio, as de adorno e outras. Segundo ele, o ser humano cria, ao longo de sua existência e em função de seu contexto cultural, certos costumes que vão se tornando tradicionais, sendo transmitidos de geração a geração, justamente porque são dotados de eficácia simbólica, ou seja, respondem a certas demandas da sociedade onde se fazem presentes, adotando significados importantes para o grupo local.

Mauss ilustra estas constatações com os exemplos que pôde observar no início do século XX sobre as técnicas corporais: as técnicas de nadar, de cavar, de marchar, de caminhar, de se portar com as mãos à mesa, de correr, entre outras. A desconcertante marcha inglesa sob o ritmo francês na primeira guerra mundial, o modo de caminhar das moças americanas e a diferença em relação às francesas - e a atenção para o fato de o incipiente cinema da época ter levado à França o estilo de andar americano. Mauss afirma, portanto, uma maneira adquirida e não natural de se comportar e se dispor o corpo. Indica o quanto as técnicas são aprendidas socialmente e o quanto a elas estamos "presos" como conseqüência da educação que tivemos, e aponta para a "natureza social do habitus, que varia não simplesmente com os indivíduos e suas imitações, mas sobretudo com as sociedades, as educações, as conveniências, as modas, os prestígios" (MAUSS, 1974, p. 214).

Importa dizer que Mauss estava atento a duas importantes questões sobre as técnicas corporais: a sua especificidade segundo as diferentes sociedades e a sua transformação ao longo das gerações. $\mathrm{Na}$ tradição, os mais velhos transmitem aos mais novos os hábitos sociais impressos e expressos pelo corpo, não de forma imutável, mas com a incorporação de transformações que se referem a novos significados atribuídos aos hábitos culturais de cada grupo.

Esses dois recortes, feitos por Mauss, relativos às especificidades das técnicas corporais - por sociedade e por geração - parecem pertinentes para a compreensão do uso e da transmissão das técnicas corporais na sociedade contemporânea. Segundo Mauss (2001, p. 115), "quando uma geração passa a outra a ciência de seus gestos e de seus atos manuais, há tanta autoridade e tradição social como quando essa transmissão se faz pela linguagem".

Tomando-se por base o conceito de técnica corporal de Mauss e as considerações de Granger sobre a transformação da técnica nos últimos séculos, é possível discutir algumas implicações sobre a concepção de técnica esportiva que deveria nortear os programas de pedagogia do esporte. Nessa perspectiva, Julio Garganta da Silva (1998) parece ter sido pioneiro ao considerar o aspecto cultural proposto por Mauss na abordagem da técnica em relação à pedagogia do esporte coletivo, mostrando que essa dimensão apresenta forte componente cultural. Segundo ele, no ensino do esporte coletivo, as técnicas corporais referem-se "às diferentes formas de utilização do corpo que permitem lidar eficazmente com os constrangimentos impostos pelas características das respectivas modalidades esportivas" (GARGANTA DA SILVA, 1998, p. 22). 
Jocimar Daolio (2002) também partiu das proposições de Mauss para rever a questão da técnica no ensino do esporte. Lançando mão de um conceito cultural de técnica corporal, em que deve ser considerado o significado de todo e qualquer movimento no seio de uma dada sociedade, propôs o ensino dos gestos técnicos não somente baseados na dimensão da eficiência mecânica, mas em contextos culturais específicos, respeitando-se também a eficácia simbólica inerente a toda ação humana.

[...] é justamente essa característica que separa o Homem dos outros animais. Enquanto esses últimos apenas reproduzem movimentos, podendo até realizá-los com certa eficiência, os humanos, além da busca da perfeição, continuamente atribuem significados culturais às suas ações, variando as formas de execução, transformando-as, criticando-as e executando-as com objetivos os mais variados possíveis (DAOLIO, 2002, p.102).

A dimensão da eficácia simbólica - conceito caro à Antropologia Social - parece importante na discussão do esporte, sobretudo em relação ao seu ensino. É notória a constatação que várias técnicas utilizadas na prática esportiva não são eficientes do ponto de vista biomecânico ou estatístico, mas, por serem eficazes do ponto de vista do seu significado, continuam sendo praticadas, tornando-se tradicionais e sendo transmitidas às gerações seguintes. Um exemplo disso é a finta no futebol, construção técnica que estatisticamente não é das mais recomendáveis, uma vez que um grande número de tentativas resulta em pequena proporção de acertos e, menos ain$\mathrm{da}$, de jogadas que resultem em gol. No entanto, driblar no futebol possui um conjunto de significados que remetem ao prazer, à brincadeira, à dominação do adversário etc., que fazem com que essa técnica perdure, para descontentamento de professores e técnicos esportivos que priorizam a prática do futebol de forma rígida e com possibilidade de vitória mais assegurada por parte de sua equipe.
Não se pretende opor os conceitos de eficiência e eficácia simbólica, como se fossem excludentes ou com significados opostos, mesmo porque o movimento biomecanicamente eficiente é dotado, inegavelmente, de significados culturais. Isso se torna mais evidente atualmente, devido ao grande poder da mídia esportiva que multiplica imagens de atuações de atletas de alto rendimento. $\mathrm{O}$ gesto esportivo oriundo dos movimentos dos atletas de alto rendimento constitui-se, sem dúvida, em técnica, aliás, das mais eficientes e, plasticamente, das mais belas. Porém, não pode ser tomado como a técnica modelar, a ser ensinada imediatamente a todos os alunos. Primeiramente, por se tratar de movimentos dos mais elaborados, demanda grande tempo de treinamento para sua perfeita manifestação; em segundo lugar, porque os alunos, culturalmente situados, podem possuir outros interesses de movimento, que levem a outras demandas em termos de execução (DAOLIO, 2002).

A consideração da dimensão da eficácia simbólica permite também compreender o esporte como fenômeno sociocultural e não somente como um conjunto de técnicas, táticas e regras específicas. Nesse sentido, a técnica esportiva não pode ser separada da dimensão dos significados culturais, dos rituais, das visões de mundo, das características de seus praticantes, das especificidades do contexto etc. O mesmo esporte definido como universal, por possuir regras comuns em todas as partes do mundo e ser organizado em federações e confederações, é, no entanto, praticado de formas diferentes, com interesses variados e significados próprios. Os gestos esportivos devem ser vistos não apenas por uma perspectiva mecânica, mas como fatos sociais totais, no sentido que deu a essa expressão Marcel Mauss, envolvendo as dimensões biológica, psicológica e, sobretudo, sociológica. Os fatos sociais são fatos tradicionais, "eles são técnicos, estéticos, econômicos, morfológicos" (MAUSS, 2001, p. 114). 
Qualquer professor que tenha atuado com grupos diferentes, em bairros ou cidades diferentes, por certo percebeu que o mesmo conteúdo esportivo insere-se de formas próprias em contextos diversos, adquirindo um caminho pedagógico específico que lhe dá sentido naquele contexto. Os interesses do grupo em questão podem ser diferentes, as experiências esportivas serem outras, os significados atribuídos àquela modalidade serem outros, e os objetivos, obviamente, serem variados. Cabe ao professor fazer a mediação entre o conhecimento esportivo a ser trabalhado com o grupo e seus interesses, experiências e demandas culturalmente determinados.

A pedagogia do esporte, com ênfase exacerbada nos aspectos técnicos em detrimento da consideração dos aspectos táticos, privilegia o "como fazer" deixando de lado o "para que ou as razões do fazer" (BAYER, 1994; GARGANTA, 1995). Isso é mais evidente em todas as modalidades esportivas coletivas e em algumas individuais, pelo caráter imprevisível que as situações de jogo e as exigências ao praticante impõem. Num jogo como o basquetebol, por exemplo, o praticante lança mão de algumas técnicas (arremesso, drible, passe etc.) para resolver demandas táticas do jogo. Saber fazer um arremesso de forma eficiente do ponto de vista biomecânico, reproduzindo movimentos dos atletas de alto nível, pode não ser suficiente para a solução de um problema colocado na dinâmica do jogo, pois as situações são imprevisíveis. Nesse exemplo, o marcador pode ser alto, o passe anterior pode chegar baixo ou curto, pode haver um companheiro melhor posicionado, enfim, situações imprevisíveis que podem fazer com que o arremesso não ocorra da forma planejada.

Desse modo, é a dimensão tática que dá sentido ao jogo. Tática deve ser pensada como a necessidade de desenvolvimento do jogo, o que é melhor de se fazer em determinada situação ou, como dito anteriormente, as "razões do fazer", que complementam e dão sentido aos "modos de fazer". Se a técnica for considerada somente como um fazer mecânico, reproduzindo rígidos modelos de execução, será perdido o caráter autoral, singular e variável da técnica como construção humana, com significados culturais específicos. Será perdida também a possibilidade de criação, de solução de problemas, de se fazer de forma singular.

Nos esportes, o uso tradicional do termo "tática" tem sido limitado, reduzindo-se aos sistemas de jogo ou a algumas jogadas ensaiadas pelo técnico. Tem sido desconsiderada a dimensão da busca de estratégias, da inteligência tática, privilegiando-se um modelo estático e pouco variável de posicionamento na quadra ou no campo. Da forma como estamos defendendo, a inteligência nos esportes não consiste em apenas possuir respostas prontas, mas em apresentar condições criativas para construir respostas eficazes (BAYER, 1994; GARGANTA, 1995).

A proposta que defendemos sugere $o$ ensino do esporte que vise a atingir todos e quaisquer alunos, de todas as idades, de todas as condições físicas, com variados interesses. Assim, não se deve insistir apenas na repetição de certos gestos esportivos tidos como os mais eficientes, pois isso desconsidera que o esporte se constitui e se expressa por um conjunto de significados que transcende a dimensão mecânica do gesto. Propomos, enfim, o ensino da cultura esportiva de forma mais democrática, singular e autoral, respeitando as especificidades culturais e as constantes ressignificações do esporte. Portanto, a pedagogia do esporte precisa refutar o modelo meramente instrumental de técnica e recuperar a dimensão simbólica inerente às práticas tradicionais humanas.

\section{Sport technique as a cultural construction: implications to Sport Pedagogy}

\footnotetext{
Abstract

This text discusses technique in sport based on references from the social and human sciences and it questions the traditional concept of technique used in the field of
} 
physical education and sports, which is taken primarily from contributions of the natural sciences. By considering technique as a set of procedures to do something, and tactics as the reasons for doing something, the text discusses its possible implications for sport pedagogy and argues for a teaching of sport culture that is more democratic, singular, and authoral, with a respect for cultural specificities and for the constant resignifications of sports.

Keywords: sport - sport culture - sport pedagogy - sport technique.

La técnica deportiva como construcción cultural: implicaciones hacia la Pedagogía del Deporte

\section{Resumen}

El texto discute la técnica deportiva partiendo de algunos referenciales de las ciencias sociales y humanas, y hace un contrapunto al concepto tradicional de técnica utilizado por el área de Educación Física y Deporte, cuya base teórica se compone primordialmente por contribuciones de las ciencias naturales. Considerando la técnica como el conjunto de maneras de hacer, y la táctica como las razones de hacer, el texto trata de las implicaciones para la pedagogía deportiva, y propone la enseñanza de la cultura deportiva de manera más democrática, singular y autoral, respetando las especificidades culturales y las constantes resignificaciones del deporte. Palabras-clave: deporte - cultura deportiva - pedagogía del deporte - técnica deportiva.

\section{Referências}

BAYER, C. O ensino dos desportos colectivos. Lisboa: Dinalivros, 1994.

BRACHT, V. Sociologia critica do esporte: uma introdução. 3. ed. Ijuí: Unijuí, 2005.

DAOLIO, J. Jogos esportivos coletivos: dos princípios operacionais aos gestos técnicos
- modelo pendular a partir das idéias de Claude Bayer. Revista Brasileira de Ciência e Movimento, Brasília, v. 10, n. 4, p. 99-103, 2002.

GARGANTA, J. Para uma teoria dos jogos desportivos colectivos. In: GRAÇA, A.; OLIVEIRA, J. (Orgs.). O ensino dos jogos desportivos. 2. ed. Porto: Centro de Estudos dos Jogos Desportivos, 1995.

GARGANTA DA SILVA, J. M. O ensino dos jogos desportivos colectivos: perspectivas e tendências. Movimento, Porto Alegre, ano 4, n. 8, p.19-27, 1998.

GEERTZ, C. A interpretação das culturas. Rio de Janeiro: Guanabara Koogan, 1989.

GRANGER, G.-G. A ciência e as ciências. São Paulo: Unesp, 1994.

MAUSS, M. Sociologia e antropologia. São Paulo: Edusp, 1974.

Ensaios de sociologia. São Paulo: Perspectiva, 2001.

ORTIZ, R. Anotações sobre o universal e a diversidade. Revista Brasileira de Educação, Rio de Janeiro, v. 12, n. 34, jan./abr. 2007.

Recebido: 29 de setembro de 2007

Aprovado: 23 de novembro de 2007

Endereço para correspondência

jocimar@fef.unicamp.br

emersonvelozo@yahoo.com.br 